\title{
Role of Maternal Glucose as a Metabolic Substrate for the Guinea Pig Conceptus
}

\author{
LOUIS L. PEETERS, CARLA M. VERKESTE, HENK C. S. WALLENBURG, PRAMOD R. SAXENA, \\ AND BERNARD K. VAN KREEL \\ Departments of Obstetrics and Gynecology [L.L.P., C.M.V., H.C.S.W., B.K.vK.], and Pharmacology [P.R.S.], \\ Erasmus University Medical School, Rotterdam, The Netherlands
}

\begin{abstract}
Our study in pregnant guinea pigs was designed to determine whether the modest fractional contribution of glucose to the late-pregnant uterine caloric uptake was due to inadequate uterine glucose supply or to diminished uterine glucose demand. To this end, uterine uptake of glucose, $\mathrm{O}_{2}$, and lactate was measured in 27 late-pregnant guinea pigs with a wide range of litter sizes. A group of 11 mid-pregnant guinea pigs served as a reference. The fractional uterine uptake of glucose in mid- and late-pregnancy was 90 and $45 \%$, respectively, confirming the indirect data calculated from different studies. In late pregnancy, uteroplacental blood flow (microspheres, $-40 \%$ ) as well as arterial glucose concentration $(-30 \%)$ had decreased relative to mid-gestation, giving rise to a $60 \%$ lower wt-specific uterine glucose supply and a $21 \%$ lower wt-specific uterine glucose uptake. Inasmuch as fetal and placental glycogen stores become rapidly depleted after the 50th day of pregnancy, the lower uterine glucose uptake in late pregnancy appears to reflect inadequate uterine glucose supply rather than diminished fetal glucose demands. In late pregnancy, uterine caloric demand per $\mathrm{kg}$ is about $60 \%$ more than in mid-gestation, most likely associated with accelerated fetal fat accretion. Inasmuch as the latter appears to be mostly fueled by nonglucose fat precursors, it could explain why the glucose fraction of the uterine caloric uptake in late pregnancy has decreased by $50 \%$ instead of $21 \%$ as compared to mid-gestation. The reduction in arterial glucose concentration in late pregnancy was independent of litter size suggesting this phenomenon is to be a maturational adaptation rather than a sign of inadequate maternal glucose production. (Pediatr Res 25:641-644, 1989)
\end{abstract}

Abbreviations

CO, cardiac output

IVC, inferior vena cava

UBF, uterine blood flow

PBF, placental blood flow

BP, systemic blood pressure

HR, mean heart rate

Hct, hematocrit

$\mathrm{G}_{\mathrm{A}}$, arterial glucose concentration

$\mathrm{L}_{\mathrm{A}}$, arterial lactate concentration

$\left[\mathrm{O}_{2}\right]_{\mathrm{A}}$, arterial oxygen concentration

[a-v], arteriovenous concentration difference

Q-G, uterine glucose uptake

$\mathrm{Q}-\mathrm{O}_{2}$, uterine $\mathrm{O}_{2}$ uptake

Received May 31, 1988; accepted January 9, 1989.

Correspondence Dr. Louis L. Peeters, Department of Obstetrics and Gynaecology, Academic Hospital Maastricht, PO Box 1918, 6201 BX, Maastricht. The Netherlands.
GTR, glucose turnover rate

$\mathbf{R}_{\mathrm{SP}}$, Spearman correlation

In the mid-pregnant guinea pig, the estimated caloric value of the uterine glucose uptake $(1,2)$ covers about $90 \%$ of the combined caloric value of fetal growth (3) and uterine oxidative metabolism $(1,2)$. Recently we observed that uterine glucose uptake in the late-pregnant guinea pig corresponds with only $45 \%$ of estimated total uterine caloric demands (4). There are two possible explanations for this phenomenon. 1) Uterine glucose demand exceeds uterine glucose supply associated with exceptionally high demands of the relatively large conceptus in this species $(3,4) .2)$ Uterine glucose requirements in late pregnancy are diminished, with a shift toward use of non-glucose fat precursors instead of glucose to fuel the accelerated fetal fat deposition in late pregnancy $(3,5,6)$.

Our study was designed to determine which of these two possibilities is responsible for the lower fractional uterine glucose uptake in the late-pregnant guinea pig. To this end, we measured uterine glucose, lactate, and $\mathrm{O}_{2}$ uptake in a large group of latepregnant guinea pigs, in which litter wt and thus uterine glucose demand varied over a wide range. A group of 11 mid-pregnant guinea pigs served as a reference group.

\section{MATERIALS AND METHODS}

A total of 38 pregnant albino guinea pigs bred in our own laboratory facility was used in this study. Dated pregnancies were obtained by using the technique of post-partum breeding (7). Details on animal housing and handling are described in a previous report (4).

Surgical techniques. Under general anesthesia polyethylene catheters were inserted into the left ventricle of the heart, the abdominal aorta, and the inferior vena cava as described in detail previously $(4,8)$. Surgery was performed between the 30 th and 38 th day of pregnancy in 11 guinea pigs and between the 44th and 50th day of pregnancy in 27 animals. Catheters were tunneled subcutaneously and exteriorized between the shoulder blades. They were not flushed after surgery. Experimental data were obtained as soon as the animal had reestablished the presurgical daily wt gain. About $3 \mathrm{~h}$ before the experiment, a polyvinyl catheter was passed under fluoroscopic guidance through the IVC catheter into one of the ovarian veins $(4,7,8)$.

Experimental protocol. BP and HR were monitored continuously throughout the experiments. At intervals of $30 \mathrm{~min}$, three sets of arterial and venous blood samples were collected for measurement of substrates and blood gases. The first and second set were followed by blood flow measurement using $15-\mu \mathrm{m}$ microspheres (NEN, Dreieich, West Germany) as described in detail previously $(4,9)$. Both blood sampling and blood flow 
measurements were performed after stable readings for BP and HR had been obtained for at least $15 \mathrm{~min}$. Simultaneously with the injection of microspheres, a reference sample was collected from the abdominal aorta at a constant withdrawal rate of 0.6 $\mathrm{ml} / \mathrm{min}$. The total amount of blood sampled during the experiments was approximately $3.5 \mathrm{ml}$. Each blood flow measurement was based on the results of two separate microsphere injections under the same experimental condition as described in a previous report (4). After the experiments, the animals were killed with an overdose of pentobarbital sodium. All catheter positions were verified and all organs were dissected. In all animals the tip of the catheter used for injection of microspheres appeared to be located in a satisfactory position in the left ventricle. The tip of the abdominal aorta catheter was located between the kidneys and the aortic bifurcation. The tip of the ovarian vein catheter was always located $1-2 \mathrm{~cm}$ inside one of the ovarian veins.

The radioactivity in each tissue aliquot and in the reference samples was determined with a well scintillation counter adapted with a 3-inch crystal (Packard Autogamma Scintillation Counter 5220, Delft, Holland). Data analysis was performed as described previously $(4,9)$. All tissue and reference samples contained at least 700 microspheres. $\mathrm{CO}$ was defined as the sum of all tissue flows. Concentrations of glucose and lactate were determined with standard enzymatic techniques after perchloric acid precipitation (10). The Hct was determined in duplicate with the microcapillary technique. The $\mathrm{Hb}$ and oxygen saturation were determined with an OSM2 apparatus (Radiometer, Copenhagen, Denmark). Blood gases and $\mathrm{pH}$ were measured with an ABL3 apparatus (Radiometer). The oxygen content was calculated from the $\mathrm{Hb}$, the oxygen saturation, and the $\mathrm{PO}_{2}(8)$.

Data presentation and statistics. The median value of three arterial concentrations and the matched venous concentrations were used to calculate the [a-v]. Uterine uptake in our study was calculated by applying the Fick principle to the experimental data from one uterine horn. The observations in the 11 midpregnant animals (group 1) were compared with those in the 27 late-pregnant animals using the Wilcoxon-Mann-Whitney test. In the 27 late-pregnant guinea pigs, the interrelations between the various hemodynamic and metabolic variables, and the interrelations of the latter variables with uterine wt were evaluated with Spearman's correlation test. A $p$ value of less than 0.05 was chosen to represent significance.

Table 1. Characteristics and experimental data of mid-pregnant guinea pigs (group $1, n=11$ ) and late-pregnant guinea pigs (group 2, $n=27)$ (means $\pm S D)$

\begin{tabular}{lcc} 
& & \\
& $\begin{array}{c}\text { Group 1 } \\
\text { (mid-trimester) }\end{array}$ & $\begin{array}{c}\text { Group 2 } \\
\text { (late pregnant) }\end{array}$ \\
\hline Characteristics & & \\
Gestational age (d) & $42 \pm 3$ & $57 \pm 3^{*}$ \\
Maternal wt (g) & $830 \pm 65$ & $1032 \pm 109^{*}$ \\
Cardiac output (ml/min) & $249 \pm 40$ & $231 \pm 40$ \\
Blood pressure (torr) & $52 \pm 6$ & $55 \pm 7$ \\
Heart rate (bpm) & $278 \pm 35$ & $280 \pm 43$ \\
Hematocrit (vol/100 ml) & $34 \pm 4$ & $34 \pm 3$ \\
& & \\
Arterial variables & & \\
Oxygen (mM) & $6.55 \pm 0.90$ & $6.47 \pm 0.71$ \\
Glucose (mM) & $6.64 \pm 0.81$ & $4.54 \pm 0.59^{*}$ \\
Lactate (mM) & $0.83 \pm 0.28$ & $1.09 \pm 0.36^{*}$ \\
& & \\
Uterine variables & & \\
Litter size & $3.7 \pm 0.6$ & $3.5 \pm 1.2$ \\
Total fetal mass (g) & $61 \pm 23$ & $207 \pm 68^{*}$ \\
Total placental mass (g) & $9.2 \pm 3.1$ & $16.2 \pm 5.4^{*}$ \\
Myometrial wt (g) & $10.3 \pm 2.6$ & $16.4 \pm 4.9^{*}$ \\
Fetal/placental wt ratio & $6.7 \pm 1.4$ & $13.3 \pm 3.3^{*}$ \\
Total UBF (ml/min) & $19.5 \pm 8.4$ & $36.5 \pm 13.6^{*}$ \\
Total PBF (ml/min) & $17.1 \pm 8.7$ & $33.2 \pm 12.9^{*}$ \\
\hline
\end{tabular}

* Group 1 different from group $2(p<0.05)$.

\section{RESULTS}

General characteristics, baseline hemodynamics, $\left[\mathrm{O}_{2}\right]_{\mathrm{A}}, \mathrm{G}_{\mathrm{A}}$, $\mathrm{L}_{\mathrm{A}}$, and some uterine variables as observed in the mid- and latepregnant groups are listed in Table 1. CO, HR, BP, Hct, and $\left[\mathrm{O}_{2}\right]_{\mathrm{A}}$ did not differ between the two groups. However, $\mathrm{G}_{\mathrm{A}}$ was about $30 \%$ lower, and $\mathrm{L}_{\mathrm{A}}$ about $30 \%$ higher in late gestation as compared to mid-pregnancy. The total litter wt was three times as high and total placental wt, fetal to placental wt ratio, and PBF twice as high in late pregnancy as in mid-gestation.

The experimental data obtained from one pregnant uterine horn in the two groups are listed in Table 2. In the late-pregnant group, mean $\mathrm{UBF} / \mathrm{kg}$ of pregnant uterus was about $40 \%$ lower, and the uterine $\mathrm{O}_{2}$ and glucose extraction was $80 \%$ higher than in mid-pregnancy. The $80 \%$ higher oxygen extraction was paralleled by an $80 \%$ increase in uterine [a-v]-O $\mathrm{O}_{2}$. In contrast, the $80 \%$ increase in glucose extraction gave rise to only a $32 \%$ increase in uterine [a-v]-glucose, most likely due to the concomitant $30 \%$ lower $\mathrm{G}_{\mathrm{A}}$. As a consequence, the late-pregnant wtspecific uterine uptake of $\mathrm{O}_{2}$ was maintained whereas that of glucose had decreased by $21 \%$ as compared to mid-gestation. The uterine lactate output expressed per $g$ of placenta did not differ significantly between mid- and late pregnancy.

The total wt of the uterine horn studied in the late-pregnant group ranged from 50 to $292 \mathrm{~g}$. Of the latter variation, $68 \%$ could be explained by variation in fetal number whereas only $11 \%$ was due to variation in gestational age (multiple linear regression). For this reason, correlations between various maternal and uterine parameters and total litter wt or total wt of sampled uterine horn were considered to be primarily a result of differences in total or ipsilateral fetal number, respectively. In late pregnancy, maternal, fetal, placental and myometrial wt

Table 2. Experimental data obtained from studied uterine horn of mid-pregnant (group $1, n=11$ ) and late-pregnant guinea pigs (group 2, $n=27$ ) (means $\pm S D$ )

\begin{tabular}{lcc}
\hline & $\begin{array}{c}\text { Group 1 } \\
\text { mid-trimester }\end{array}$ & $\begin{array}{c}\text { Group 2 } \\
\text { late pregnant }\end{array}$ \\
\hline Wt of horn (g) & $54 \pm 28$ & $156 \pm 66^{*}$ \\
Fetal no. & $2.5 \pm 0.9$ & $2.2 \pm 0.9$ \\
Total fetal mass (g) & $41 \pm 23$ & $136 \pm 61^{*}$ \\
Total placental mass (g) & $6.3 \pm 3.1$ & $10.5 \pm 4.3^{*}$ \\
Myometrial wt (g) & $6.3 \pm 2.2$ & $9.3 \pm 3.7^{*}$
\end{tabular}

Blood flow $(\mathrm{ml} / \mathrm{min})$

Total horn

Per kg horn

Placentas (total)

Per 100 g placenta

To myometrium

Per $100 \mathrm{~g}$ myometrium

\begin{tabular}{|c|c|}
\hline $13.2 \pm 7.0$ & $19.0 \pm 8.1^{*}$ \\
\hline $251 \pm 84$ & $146 \pm 37^{*}$ \\
\hline $11.7 \pm 6.9$ & $17.2 \pm 7.6^{*}$ \\
\hline $180 \pm 58$ & $201 \pm 79$ \\
\hline $1.5 \pm 1.0$ & $1.8 \pm 0.8$ \\
\hline $26 \pm 16$ & $18.4 \pm 7.3$ \\
\hline
\end{tabular}

(a-v) gradients

Oxygen $(\mathrm{mM})$

Glucose (mM)

$2.32 \pm 0.60$

$0.62 \pm 0.27$

Lactate (mM)

$-0.22 \pm 0.07$

$4.31 \pm 0.67 *$

$0.82 \pm 0.38^{*}$

$-0.38 \pm 0.15^{*}$

Metabolic quotients

$\mathrm{G} / \mathrm{O}_{2}$ quotient

$1.71 \pm 0.76$

$1.11 \pm 0.51^{*}$

$\mathrm{L} / \mathrm{O}_{2}$ quotient

$0.30 \pm 0.11$

$0.26 \pm 0.10^{*}$

$(\mathrm{G}+\mathrm{L}) / \mathrm{O}_{2}$ quotient

$1.41 \pm 0.68$

$0.86 \pm 0.53^{*}$

Uterine uptakes ( $\mu \mathrm{mol} /$ min)

Oxygent

Glucose $†$

$\begin{array}{cc}525 \pm 185 & 607 \pm 146 \\ 164 \pm 62 & 130 \pm 49^{*} \\ -44 \pm 12 & -62 \pm 25\end{array}$

* Group 1 different from group $2(p<0.05)$

$\dagger$ Expressed per $\mathrm{kg}$ of gravid uterus.

$\ddagger$ Expressed per $\mathrm{g}$ of placenta. 
were higher in animals with a larger conceptus. $\mathrm{CO}$ and $\mathrm{HR}$ varied independently of litter wt, in contrast to $\mathrm{BP}$ which correlated negatively with litter wt $\left(\mathrm{R}_{\mathrm{SP}}=-0.52, p<0.05\right)$. The three arterial concentrations varied independently from the wt of uterus with conceptus whereas the UBF $/ \mathrm{kg}$ correlated inversely with the latter $\left(\mathrm{R}_{\mathrm{SP}}=-0.35, p<0.05\right)$. A compensatory higher uterine gradient for $\mathrm{O}_{2}$ in guinea pigs with a relatively large sampled uterine horn $\left(\mathrm{R}_{\mathrm{SP}}=+0.38, p<0.05\right)$ was not observed for glucose. Consequently, the wt-specific uterine uptake of $\mathrm{O}_{2}$ varied independently of uterine horn wt, whereas that of glucose decreased with increasing uterine horn wt $\left(\mathrm{R}_{\mathrm{SP}}=0.68, p<0.05\right)$. The wt-specific blood flows to placentas and myometrium, and all other uterine variables listed in column 2 of Table 2, varied independently of the wt of the sampled uterine horn.

To compare mid-pregnant with late-pregnant uterine glucose uptake as fraction of total uterine caloric uptake, we calculated the caloric equivalent of the daily deposition of new fetal tissue and the caloric equivalent of the daily consumption of oxygen by the pregnant uterus for two hypothetical guinea pigs of 42 and 58 days, respectively. The results of these calculations are listed in Table 3 . Fetal caloric accretion was calculated by using the equations based on the fractional caloric value of the fetus throughout guinea pig pregnancy (3). Inasmuch as placental and myometrial growth are small relative to that of the fetus, their contribution to the uterine caloric demand was assumed to be negligible. The mean values for fractional uterine wt, as shown in Table 2, were used to convert values per $\mathrm{kg}$ of fetus to values per $\mathrm{kg}$ of pregnant uterine horn. The mean values for uterine uptake listed in Table 2 were used to calculate the caloric value for oxygen and "net" glucose uptake (equals uterine glucose uptake minus the equivalent of uterine lactate output).

\section{DISCUSSION}

The purpose of our study was to determine whether the modest fractional contribution of glucose to the uterine caloric uptake in late pregnancy as compared to mid-gestation indicates inadequate glucose supply by the mother or diminished glucose demand by the conceptus. The polytocous character of guinea pig pregnancy offers the possibility to separate the effects related to maturation from those related to the growing size of the concep-

Table 3. Estimated caloric value of daily accretion of new fetal tissue* and uterine oxygen consumption and caloric value of net uterine glucose uptake in two hypothetical fetuses $\dagger$

\begin{tabular}{|c|c|c|}
\hline & 42 days & 58 days \\
\hline \multicolumn{3}{|c|}{$\begin{array}{l}\text { Estimated daily accretion of } \\
\text { fetal tissue in } \mathrm{g} / \mathrm{kg} \text { and } \\
(\mathrm{kcal} / \mathrm{kg})\end{array}$} \\
\hline Water & $76.2(0)$ & $39.0(0)$ \\
\hline Fat & $3.3(31)$ & $8.9(83)$ \\
\hline Protein & $9.1(50)$ & $13.3(73)$ \\
\hline Other tissue & $4.0(13)$ & $5.9(19)$ \\
\hline \multicolumn{3}{|l|}{ Total growth } \\
\hline$/ \mathrm{kg}$ fetus & $92.6(94)$ & $67.1(175)$ \\
\hline /kg uterine horn & $71.2(72)$ & $58.0(153)$ \\
\hline Oxygen & $-(83)$ & $-(96)$ \\
\hline \multicolumn{3}{|l|}{ Caloric demands of uterine } \\
\hline \multicolumn{3}{|c|}{$\begin{array}{l}\text { Caloric equivalent of glucose } \\
\text { uptake } \$\end{array}$} \\
\hline in $\mathrm{kcal} / \mathrm{kg} /$ day & 136 & 88 \\
\hline in fraction of demand & $88 \%$ & $39 \%$ \\
\hline
\end{tabular}

* The growth of each type of fetal tissue is calculated on the basis of data reported by Sparks et al. (3). Values are expressed per $\mathrm{kg}$ of wet wt.

† Gestational ages, uterine fractional wt, and uptakes corresponding with the mean values for the two groups in Table 2.

$\$$ The caloric equivalent of $\mathrm{O}_{2}$ equals $109.7 \mathrm{kcal} / \mathrm{mol}$ of $\mathrm{O}_{2}$ (STP).

$\S$ The caloric equivalent of glucose equals $740 \mathrm{kcal} / \mathrm{mol}$. tus. For instance, the decline in $\mathrm{G}_{\mathrm{A}}$ toward term is not paralleled by an inverse relationship between $G_{A}$ and total wt of the conceptus in late pregnancy. Consequently, the lower $G_{A}$ in late pregnancy is likely to be purely maturational. In contrast, with advancing pregnancy the wt-specific UBF decreases more in guinea pigs with a larger litter wt. Thus, the lower UBF per unit wt in late pregnancy is probably a result of a combined effect of maturation and increasing litter wt.

Table 2 shows that the wt-specific uterine glucose uptake in late pregnancy is $21 \%$ lower than in mid-gestation. Inasmuch as glycogen stores in both fetus and placenta become rapidly depleted after the 50th day of guinea pig pregnancy (van Kreel BK, unpublished data), the lower uterine glucose uptake in late pregnancy is to be considered a result of diminished uterine glucose supply rather than of decreased uterine glucose demand. As a matter of fact, the $21 \%$ lower uterine glucose uptake was paralleled by a $60 \%$ lower wt-specific uterine glucose supply (calculated from Tables 1 and 2) due to the simultaneous decrease in $\mathrm{UBF} / \mathrm{kg}$ and $\mathrm{G}_{\mathrm{A}}$. Both decreases appear to have a different origin.

A lower $G_{A}$ in late gestation has been previously described for the guinea pig $(2,11)$ and ewe (12). The transplacental transfer of glucose is primarily dependent on the concentration gradient across the placenta $(13,14)$. It follows that the smaller increase in uterine $[\mathrm{a}-\mathrm{v}]$ glucose difference $(+32 \%)$ than in uterine glucose extraction $(+80 \%)$ with pregnancy appears to be caused by the concomitant decrease in $G_{A}$. Therefore, the lower $G_{A}$ is most likely responsible for at least part of the lower uterine glucose uptake in late pregnancy. Inasmuch as the $\mathrm{G}_{\mathrm{A}}$ reduction is purely related to gestational age, maturational aspects of pregnancy, such as changing levels of placental hormones, may be involved in lowering the setpoint for $G_{A}$. The lack of correlation between $\mathrm{G}_{\mathrm{A}}$ and late-pregnant litter wt indicates that the decline in $\mathrm{G}_{\mathrm{A}}$ with pregnancy is not caused by a gradually developing discrepancy between maximum maternal glucose production and rapidly increasing uterine glucose demands.

The fall in UBF $/ \mathrm{kg}$ toward term has also been observed in the ewe (15). Our data suggest that PBF in guinea pig pregnancy increases in proportion to placental rather than to fetal wt (Table 1). Therefore, it is likely that the about 30 to $40 \%$ lower wtspecific UBF in the late-pregnant guinea pig is directly related to the approximately $30 \%$ slower growth rate of the placenta relative to that of the fetal body. In contrast to the $G_{A}$, the $U B F / k g$ correlated inversely with litter wt. As a consequence, the lower late-pregnant uterine glucose supply $/ \mathrm{kg}$ in guinea pigs with a large litter is entirely due to a concomitant lower UBF $/ \mathrm{kg}$.

In our late-pregnant group the mean wt-specific uterine glucose uptake was $21 \%$ and the glucose fraction of the uterine caloric uptake was $50 \%$ lower than in midpregnancy (Table 3). The larger decline in fractional uterine glucose uptake appears to be directly related to the $60 \%$ higher total uterine caloric uptake per $\mathrm{kg}$ in late pregnancy. Inasmuch as fat accretion constitutes an important part of fetal tissue growth in the late-pregnant guinea pig, it is conceivable that the extra calories are mostly nonglucose fat precursors $(5,6,16)$.

It has been postulated that the relatively high wt-specific glucose utilization in small mammals, such as the guinea pig, may give rise to a smaller difference in glucose utilization rate between adult and fetal wt-specific glucose utilization in these mammals (17). However, the twice as high late-pregnant uterine glucose uptake in our study as compared to that reported for the adult nonpregnant guinea pig $(56 \mu \mathrm{mol} / \mathrm{min} / \mathrm{kg})(18)$, does not support this hypothesis. In an attempt to confirm our data, we estimated fetal glucose uptake in the late-pregnant guinea pig using two regression equations. The first equation describes the relationship between total maternal GTR and fetal wt (FW): GTR in $\mathrm{mg} / \mathrm{kg}=0.014 \mathrm{FW}+6.81$ (17). The second equation describes the relationship between fetal to maternal wt ratio (FW/MW) and fetal wt, and was determined for a comparable group of late-pregnant guinea pigs from our laboratory: FW/ $\mathrm{MW}=0.000758 \mathrm{FW}+0.0471(n=36$, Pearson correlation 
coefficient $=0.89, p<0.0001$ ) . If maternal glucose utilization is assumed to be equal to the GTR, and neither late-pregnant fetal nor nonuterine maternal glucose utilization vary as a function of fetal weight, fetal and nonuterine maternal glucose utilization, calculated with these two equations, amount to 134 and 33 $\mu \mathrm{mol} / \mathrm{min} / \mathrm{kg}$, respectively. This calculated value for fetal glucose utilization is almost the same as the one we measured for uterine glucose uptake and, therefore, supports our experimental data on uterine glucose uptake.

The lactate gradient across the adequately oxygenated latepregnant uterus is about $70 \%$ higher than in midgestation. This increase seems to be entirely related to the lower blood flow in late pregnancy as suggested by the similar lactate output per $g$ of placenta in mid- and late pregnancy. The absence of an inverse relation between uterine lactate gradient and wt-specific UBF supports the concept that all uterine lactate is produced aerobically, most likely selectively by the placenta $(19,20)$. The lack of a decrease in uterine lactate output in late pregnancy suggests that fetal glucose uptake suffers more from the lower uterine glucose supply than does placental glucose uptake.

Among the hemodynamic variables, only BP decreased with litter wt. One can speculate that either the mechanical hemodynamic consequences or the hormonal effects of the increase in placental mass with litter wt lowers the setpoint of the baroreceptor. However, neither the physiologic meaning nor a triggering mechanism for this adaptation in BP is fully understood.

The results of this study in mid- and late-pregnant guinea pigs suggest that glucose availability to the conceptus is modulated by two independent mechanisms. The UBF may be considered as the "safeguard" of the maternal systemic circulation and may be particularly important for short-term modulation of placental transfer in late pregnancy. The $\mathrm{G}_{\mathrm{A}}$ may be more a safeguard of the maternal metabolism with predominantly a long-term modulating effect on transplacental glucose transfer. The regulation of the setpoint for $G_{A}$ is largely obscure, as is the possible interrelation between these two variables.

\section{REFERENCES}

1. Peeters LLH, Sparks JW, Grutters G, Girard J, Battaglia FC 1982 Uteroplacental blood flow during pregnancy in chronically catheterized guinea pigs. Pediatr Res 16:716-720

2. Block SM, Johnson RL, Sparks JW, Battaglia FC 1988 Uterine metabolism of the pregnant guinea pig as a function of gestational age. Pediatr Res 23:4549

3. Sparks JW, Girard J, Callikan S, Battaglia FC 1985 Growth of the fetal guinea pig: physical and chemical characteristics. Am J Physiol 248.E132-E139

4. Peeters LLH, Martensson L, van Kreel BK, Saxena PR, Wallenburg HCS 1986 Movement of oxygen, glucose, and lactate across the uterus of the awake near-term guinea pig. Pediatr Res 20:730-734

5. Jones CT 1976 Lipid metabolism and mobilisation in the guinea pig during pregnancy. Biochem J 156:357-365

6. Thomas CR, Lowy C 1984 Contribution of circulating maternal lipids to fetal tissues in the guinea pig. J Dev Physiol 6:143-151

7. Peeters LLH, Martensson L, Gilbert M, Penicaud L 1984a The pregnant guinea pig, rabbit and rat as unstressed catheterized models. In: Nathanielsz PW (ed) Animal Models in Fetal Medicine, Vol IV, Perinatology Press Inc, Ithaca, NY, pp 77-108

8. Peeters LLH, Martensson L, van Kreel BK, Wallenburg HCS 1984b Uterine arterial and venous concentrations of glucose, lactate, ketones, free fatty acids, and oxygen in the awake pregnant guinea pig. Pediatr Res 18:11721175

9. Peeters LLH, Verkeste CM, Saxena PM, Wallenburg HCS 1987 Hemodynamic effects of isovolemic hemodilution and hemoconcentration in the awake late-pregnant guinea pig. Pediatr Res 21:584-589

10. Bergmeyer HU (ed) 1974 Methods of Enzymatic Analysis, Vols 2-4. Academic Press, Inc, New York

11. Sparks JW, Pegorier JP, Girard J, Battaglia FC (1980) Substrate concentration changes during pregnancy in the guinea pig studied under unstressed steadystate conditions. Pediatr Res 15:1340-1344

12. Hay WW Jr, Sparks JW, Wilkening RB, Battaglia C, Meschia G 1983 Partition of maternal glucose production between conceptus and maternal tissues in sheep. Am J Physiol 245:E347-350

13. Simmons MA, Battaglia FC, Meschia G 1979 Placental transfer of glucose. J Dev Physiol 1:227-243

14. Meschia G 1982 The function of the placenta as it relates to the transport of metabolic substrates to the fetus. In: CT Jones ed Biochemical Development of the Fetus and Neonate. Elsevier Biomed Press, Amsterdam, pp 495-513

15. Bell AW, Kennaugh JM, Battaglia FC, Makowski EL, Meschia G 1986 Metabolic and circulatory studies of fetal lamb at mid-gestation. Am $\mathbf{J}$ Physiol 250:E538-E544

16. Thomas CR, Lowy C 1987 The interrelationships between circulating maternal esterified and nonesterified fatty acids in pregnant guinea pigs, and their relative contributions to the fetal circulation. J Dev Physiol 9:203-214

17. Gilbert M, Sparks JW, Girard J, Battaglia FC 1985 Effects of fasting on glucose turnover rate and metabolite levels in conscious pregnant guinea pigs. Biol Neonate 48:90-99

18. Gilbert M, Sparks JW, Girard J, Battaglia FC 1982 Glucose turnover rate during pregnancy in the conscious guinea pig. Pediatr Res 16:310-313

19. Carstensen MH, Leichtweiss HP, Schroeder H 1982 The metabolism of the isolated artificially perfused guinea pig placenta. Excretion of hydrogen ions, ammonia, carbon dioxide and lactate, and the consumption of oxygen and glucose. J Perinat Med 147:147-153

20. Sparks JW, Hay W Jr, Bonds D, Meschia G, Battaglis FC 1982 Simultaneous measurements of lactate turnover and umbilical lactate uptake in the fetal lamb. J Clin Invest 70:179-192 